\title{
Microstructure and Mechanical Properties of Low-Carbon Q235 Steel Welded Using Friction Stir Welding
}

\author{
Hongduo Wang ${ }^{1,3} \cdot$ Kuaishe Wang $^{1,2} \cdot$ Wen Wang $^{1,2} \cdot$ Yongxin $\mathrm{Lu}^{3} \cdot$ Pai Peng ${ }^{1,2} \cdot$ Peng Han $^{1,2} \cdot \mathrm{Ke}^{\text {Qiao }}{ }^{1,2}$. \\ Zhihao Liu ${ }^{1,2} \cdot$ Lei Wang ${ }^{3}$
}

Received: 19 April 2020 / Revised: 14 June 2020 / Accepted: 18 June 2020 / Published online: 14 August 2020

(c) The Chinese Society for Metals (CSM) and Springer-Verlag GmbH Germany, part of Springer Nature 2020

\begin{abstract}
This study focuses on the microstructure and mechanical properties of the joints of Q235 mild steel, which was formed by the friction stir welding (FSW). The results indicated that, after the FSW, the heat-affected zone (HAZ) of the retreating side $\left(\mathrm{HAZ}_{\mathrm{RS}}\right)$ and the $\mathrm{HAZ}$ of the advancing side $\left(\mathrm{HAZ}_{\mathrm{AS}}\right)$ recovered under the influence of the heating cycle. The transformation of the phases in the thermo-mechanically affected zone (TMAZ) of the retreating side (TMAZ $Z_{R S}$ ), the stir zone (SZ) and the TMAZ of the advancing side $\left(\mathrm{TMAZ}_{\mathrm{AS}}\right)$ generated the pearlite and acicular ferrite. The continuous dynamic recrystallization occurred in all the three zones, whereas the grains were refined. The SZ mainly consisted of $D_{1}, D_{2}$ and $F$ shear textures, while the $\mathrm{TMAZ}_{\mathrm{AS}}$ was made up of only the $F$ shear texture. The fine-grained structure, pearlite and the acicular ferrite improved the hardness and tensile strength of the joint. Its ultimate tensile strength was $479 \mathrm{MPa}$, which was $1.3 \%$ higher than that of the base metal. However, the uniform elongation was $16 \%$, which showed a decrease of $33 \%$. The fracture was a ductile fracture with the appearance of dimples. Besides, the joints of the FSW showed an excellent bending performance.
\end{abstract}

Keywords Low-carbon steel $\cdot$ Friction stir welding $\cdot$ Recrystallization $\cdot$ Phase transformation $\cdot$ Mechanical properties

\section{Introduction}

The mild steel has been widely used in petroleum, chemical, natural gas, automobile and ship-building industries due to its low cost and high processing capability [1]. Generally, the mild steels are welded using the traditional fusion welding techniques, such as manual arc welding [2], molten electrode gas shielded arc welding [3] and the submerged arc welding [4]. However, these traditional fusion welding techniques are prone to cause problems, such as the solidified

Available online at http://link.springer.com/journal/40195.

Wen Wang

wangwen2016@126.com

Kuaishe Wang

wangkuaishe888@126.com

1 School of Metallurgical Engineering, Xi' an University of Architecture and Technology, Xi' an 710055, China

2 National and Local Joint Engineering Research Center for Functional Materials Processing, Xi' an 710055, China

3 School of Materials Science and Engineering, Xi' an Shiyou University, Xi' an 710065, China cracks, porosity, the segregation of alloying elements and the grain coarsening during the process of welding, which lead to lower performance of the welded joints [5, 6]. The solid-state joining technology can solve the inherent defects in the solidified structure, which are caused by the traditional fusion welding technology [7, 8]. Due to this reason, it can be considered a suitable method for high-quality welding of mild steel.

The friction stir welding (FSW) was invented by the Welding Institute in 1991 for the joining of aluminum alloys $[9,10]$. During the process of FSW, a high-speed rotating stir pin is inserted into the joint of the welding plate until the shoulder comes in close contact with the material to be welded. The frictional heat softens the material, whereas the stirring of the stir pin causes the plastic to flow and mixes the materials at the joint, which finally leads to achieving the solid-state joining between the materials [11, 12]. As a solid-state joining technology, the FSW has a low welding temperature and a short welding time [13]. Therefore, FSW can effectively avoid the solidified structural defects caused by the traditional fusion welding technology during mild steel welding. The refinement, homogenization and densification of the microstructure during the process of welding 
can significantly enhance the strength of the joint. Additionally, lower welding heat input can reduce the welding deformation [7]. Meanwhile, the tool is also the key point to get sound joint. The material flow and the temperature were affected by the profile of tool $[14,15]$.

At present, the FSW has been widely applied to materials having low melting points, such as $\mathrm{Al}, \mathrm{Mg}$ and $\mathrm{Cu}$ alloys [16-18], and has shown a great potential in various industrial fields [19-21]. In recent years, with the development of tool materials, the FSW for the materials having high melting points has received more attention of the researchers [22]. For example, the process of the FSW for steels [23-25], titanium alloys [26, 27] and nickel alloys [28, 29] has been widely studied, especially for the steels $[21,30]$. However, for the FSW of the mild steel, most of the available studies focus on the optimization of parameters and the effects of the FSW on the microstructure and mechanical properties. Fujii et al. [23] performed FSW on three steels with different carbon contents using a fixed rotation speed and variable welding speeds. The effects of the variations in the parameters and the carbon contents on the microstructures and mechanical properties of the stir zone were analyzed. The study of the FSW on the S12C mild steel indicated that, under different welding parameters, the low heat input led to high microhardness and tensile strength. At a rotation speed of $400 \mathrm{rpm}$ and a welding speed of $400 \mathrm{~mm} / \mathrm{min}$, the transformation of the phase did not occur during the process of welding, when the peak temperature was below $\mathrm{Ac}_{1}$. Zhou et al. [31] also studied the microstructure and mechanical properties of Q235 mild steel using the FSW at different welding speeds and a fixed rotation speed. The results indicated that the joint included four zones, which were the base metal (BM), SZ, TMAZ and the HAZ. During the process of FSW, the phase transformation and the dynamic recrystallization occurred in the SZ. The grain size decreased with the increase in the welding speed. The tensile strength and the elongation of the joint were lower than those of the BM, and the fracture was located in the HAZ. In contrast, Husain et al. [32] used a fixed welding speed to perform FSW on the mild steel at different speeds and studied the effects of welding heat and the deformation on the microstructure of the SZ. In the process of FSW, the temperature of the SZ was higher than the $\mathrm{Ac}_{3}$ and a phase transformation occurred during the process of welding. As a result, the structure of the joint was composed of ferrite and bainite. The continuous dynamic recrystallization refined the grains and increased the proportion of high-angle grain boundaries (HAGBs). These variations in the composition and grain enhanced the hardness of the SZ.
The above-mentioned studies have demonstrated the feasibility of the application of FSW to mild steel and have provided information on the evolution of the microstructures, such as the grains and the phase transformations. However, the relationship between the microstructure and the mechanical properties is rarely studied. Therefore, in this study, the FSW of Q235 mild steel was developed. On the basis of the characterization of the microstructures of each zone in the joint, the effects of the microstructure on the mechanical properties of the joint of FSW were studied.

\section{Experimental}

\subsection{Materials and FSW Experiments}

In this study, hot-rolled Q235 mild steel plates with a dimension of $100 \mathrm{~mm} \times 60 \mathrm{~mm} \times 3 \mathrm{~mm}$ were used for the FSW butt welding. The chemical composition of the steel is listed in Table 1. The transformation temperatures of $\mathrm{Ac}_{1}$ and $\mathrm{Ac}_{3}$ of Q235 mild steel were calculated to be $737 \pm 24{ }^{\circ} \mathrm{C}$ and $846 \pm 35^{\circ} \mathrm{C}$, respectively [33].

The process of the FSW was performed on a modified vertical milling machine with the displacement control, and under a rotation speed of $475 \mathrm{rpm}$ and a welding speed of $47.5 \mathrm{~mm} / \mathrm{min}$ (Fig. 1a). The WC-Co stir pin consisted of a hexagonal cone-shaped needle and a cylindrical shoulder, as shown in Fig. 1b. The plunge depth of the shoulder was $0.2 \mathrm{~mm}$ with the inclination of $2^{\circ}$ and the welding pressure of $20 \mathrm{kN}$. The direction of the welding was perpendicular to the direction of the rolling of the plate.

\subsection{Characterization of the Microstructure}

After the process of FSW, the metallographic specimens and the scanning electron microscopy (SEM) specimens were cut perpendicular to the WD. After mechanical polishing, the cross sections of the metallographic specimens and the SEM specimens were etched with a solution of nitric acid-ethanol. An optical microscope (OM, Neophot-21) and a SEM (JSM-6700F) were used to observe the microstructure. The electron backscatter diffraction (EBSD) specimens were cut perpendicular to the WD. The specimens were electrolytically polished using a solution of $10 \%$ perchloric acid and $90 \%$ ethanol at a voltage of $25 \mathrm{~V}$ and temperature of $-35^{\circ} \mathrm{C}$. The acquisition of the EBSD image was conducted using a fully automated HKL-EBSD system, which was connected to the ZEISS MERLIN compact field emission SEM.
Table 1 Chemical composition of the Q235 mild steel (wt\%)

\begin{tabular}{|c|c|c|c|c|c|c|c|c|c|}
\hline $\mathrm{C}$ & $\mathrm{Mn}$ & $\mathrm{Si}$ & $\mathrm{Ni}$ & Mo & $\mathrm{V}$ & $\mathrm{Cu}$ & $\mathrm{P}$ & $S$ & $\mathrm{Fe}$ \\
\hline 0.167 & 0.284 & 0.162 & 0.004 & 0.001 & 0.001 & 0.004 & 0.021 & 0.010 & $\mathrm{Bal}$ \\
\hline
\end{tabular}




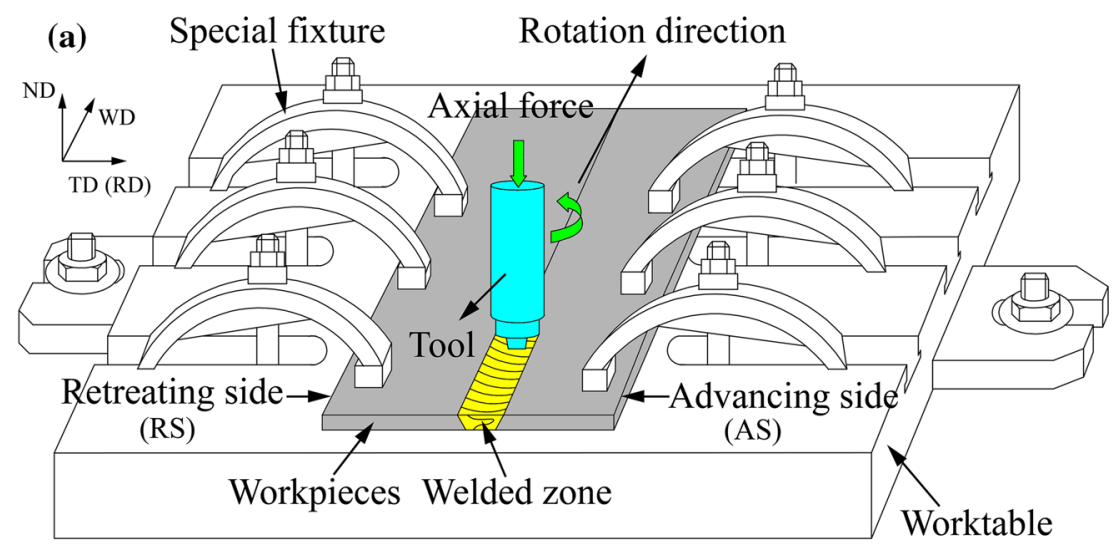

(b)

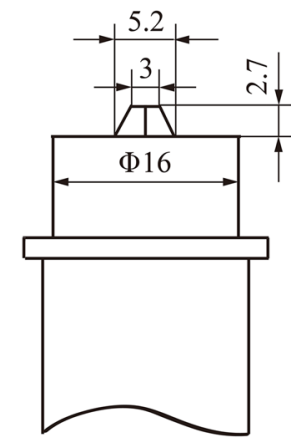

Fig. 1 a Schematic diagram of the FSW, b dimensions of the stir pin, WD: direction of the welding, TD: transverse direction, ND: normal direction, RD: direction of the rolling of the plate, measured in $\mathrm{mm}$

The acceleration voltage was $20 \mathrm{kV}$, while the step size was $0.5 \mu \mathrm{m}$. The EBSD data were acquired using the six Kikuchi patterns in order to minimize the index error of the index mode. In all the cases, a minimum of $90 \%$ of the scanned area was indexed. The proportion of the recrystallized grains was calculated by the misorientation angle in HKL CHANNEL5 software (Oxford Instruments).

\subsection{Microhardness Test}

In order to test the microhardness of the specimen, it was cut perpendicular to the WD with the dimensions of $22 \mathrm{~mm} \times 3 \mathrm{~mm} \times 10 \mathrm{~mm}$. The microhardness test was performed on the cross section (TD-ND) of the specimen using a HXD-1000 microhardness tester. The load was $300 \mathrm{~g}$, and the holding time was $10 \mathrm{~s}$. The test was performed at the interval of $0.5 \mathrm{~mm}$ in the horizontal and vertical directions. Finally, a matrix algorithm was performed for the data analysis to obtain a distribution map of the microhardness.

\subsection{Tensile Performance Test}

The tensile specimens were cut perpendicular to the WD and ground and polished to obtain smooth surfaces. The dimensions of the gauge section of the FSW joint's tensile specimen were $32 \mathrm{~mm} \times 6 \mathrm{~mm} \times 2.5 \mathrm{~mm}$. In order to obtain the tensile properties of $\mathrm{SZ}$, a small tensile specimen with the gauge dimensions of $3 \mathrm{~mm} \times 2 \mathrm{~mm} \times 2.5 \mathrm{~mm}$ was used. In the tensile specimen, the gauge length was entirely located in the SZ (Fig. 2). The tensile test was performed at room temperature using an Instron 8801 testing machine according to the standard of ASTM-E8 [34]. During the test, the tensile speed was $1.5 \mathrm{~mm} / \mathrm{min}$. Each test was repeated for at least three times to evaluate the reliability of the data. The surface of the fracture of the tensile specimen was characterized by SEM.

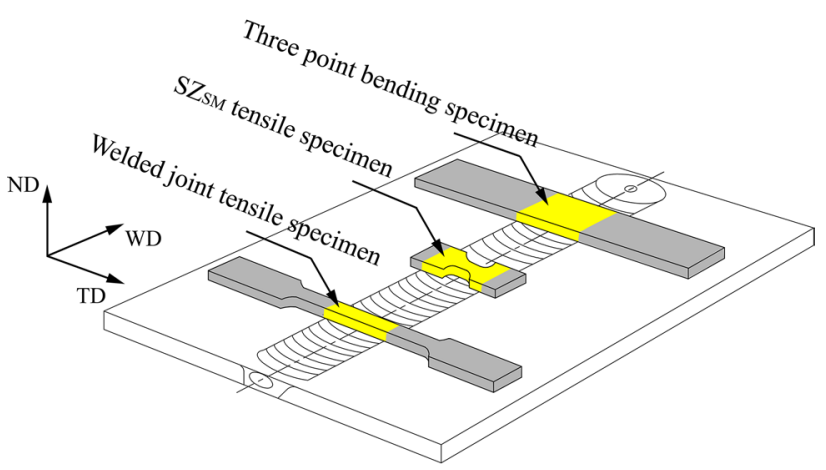

Fig. 2 Sampling diagrams of the FSW joint, the tensile specimen of the $\mathrm{SZ}$ and the three-point bending specimen

\subsection{Bending Performance Test}

The three-point bending specimens were cut perpendicular to the WD (Fig. 2), which were then ground and polished to obtain the smooth surfaces. The three-point bending test was designed according to the ISO standard [35]. The bending test was performed at room temperature using the Instron 8801 testing machine. The bending speed was $1.5 \mathrm{~mm} / \mathrm{min}$, which resulted in a $180^{\circ} \mathrm{U}$-shaped bending. Each test was repeated for at least three times to evaluate the reliability of the data. The bending strength was calculated as follows [36]:

$\sigma=\frac{3 \times F \times L}{2 \times b \times h^{2}}$,

where $F$ denotes the force applied at the center of the span, $L$ denotes the span, $b$ denotes the width of the specimen and $h$ denotes the thickness of the specimen. 


\section{Results and Discussion}

\subsection{Macrostructure of the Joint}

Figure 3 shows the cross-sectional macrostructure of the FSW joint. There were no structural defects, such as the grooves and cavities in the cross-sectional structure of the joint. According to the characteristics of the microstructure, the joint could be divided into six zones, which were the $\mathrm{BM}$, the HAZ of the retreating side $\left(\mathrm{HAZ}_{\mathrm{RS}}\right)$, the TMAZ of the retreating side $\left(T M A Z_{R S}\right.$ ), the SZ, the TMAZ of the advancing side $\left(\mathrm{TMAZ}_{\mathrm{AS}}\right)$ and the $\mathrm{HAZ}$ of the advancing side $\left(\mathrm{HAZ}_{\mathrm{AS}}\right)$.

\subsection{Microstructure of BM}

Figure 4 shows the microstructure of the BM. It can be seen that the microstructures of the BM mainly consisted of the ferrite and pearlite, where the pearlites were distributed on the boundaries of the ferrite grain (Fig. 4a). The pearlite had a lamellar morphology with the lamellar spacing of $0.7-0.8 \mu \mathrm{m}$, whereas the cementite was intermittently rod shaped or granular in shape (Fig. 4b). The ferrite grains were non-uniformly distributed and had an average grain size of $5.7 \mu \mathrm{m}$ (Fig. 4c). The proportion of HAGBs was $27 \%$ (Fig. 4d), whereas the proportion of the recrystallized grains was $15.3 \%$ (Fig. 4e).

\subsection{Microstructure of the Joint}

Figure 5 shows the microstructure of the each zone of the joint. The microstructures of the $\mathrm{OMs}$ of the $\mathrm{HAZ}_{\mathrm{RS}}$ and $\mathrm{HAZ}_{\mathrm{AS}}$ were similar to $\mathrm{BM}$ and consisted of the ferrite and pearlite, i.e., without phase transformation (Fig. 5a, e). As compared to the BM, the clusters of the pearlite had the smaller lamellar spacing with more uniform distribution due to the heating cycle (Fig. 5f, j). It was inferred that the peak temperatures of $\mathrm{HAZ}_{\mathrm{RS}}$ and $\mathrm{HAZ}_{\mathrm{AS}}$ were lower than the $A c_{1}$ [32]. The microstructures of the $\mathrm{TMAZ}_{\mathrm{RS}}, \mathrm{SZ}$ and $\mathrm{TMAZ}_{\mathrm{AS}}$ consisted of the proeutectoid ferrite and pearlite. The proeutectoid ferrite consisted of the blocky ferrite, grain boundary ferrite and the acicular ferrite. During the process of the welding, these zones underwent different degrees of phase transformation due to different heating cycles and strains. The microstructures showed some differences, which were mainly reflected in the morphology and quantitative characteristics of ferrite and pearlite. The $\mathrm{TMAZ}_{\mathrm{RS}}$ presented acicular ferrite and coarse blocky ferrite (Fig. 5b). The layers of the pearlite were widely spaced and non-uniformly distributed. The cementite exhibited short rod shaped or granular (Fig. 5g). The SZ showed grain boundary ferrite and fine acicular ferrite (Fig. 5c). The lamellar spacing of the pearlite was smaller and had a relatively uniform distribution. The cementite exhibited a linear shape

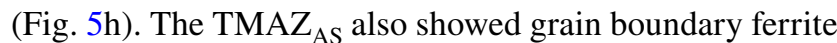
and fine acicular ferrite (Fig. 5d). The lamellar spacing of the pearlite was smaller and had a non-uniform distribution. The cementite presented several appearances, which included linear, granular and short rod-shaped appearances (Fig. 5i). Within these three zones, the descending sequence of the contents of the acicular ferrite was found in the order of: $\mathrm{TMAZ}_{\mathrm{RS}}>\mathrm{TMAZ}_{\mathrm{AS}}>\mathrm{SZ}$. However, the contents of pearlite presented the opposite sequence, which was in the following descending order: $\mathrm{SZ}>\mathrm{TMAZ}_{\mathrm{AS}}>\mathrm{TMAZ}_{\mathrm{RS}}$. Furthermore, the trend in the refined degree of the acicular ferrite was found in the order (fine to coarse) of: $\mathrm{SZ}>\mathrm{TMAZ}_{\mathrm{AS}}>\mathrm{TMAZ}_{\mathrm{RS}}$.

The peak temperature of SZ could be calculated using Eq. (2) $[8,37]$.

$\frac{T_{\text {peak }}}{T_{m}}=K\left[\frac{\omega^{2}}{2.362 \mathrm{~V} \times 10000}\right]^{\alpha}$,

where $T_{\text {peak }}$ denotes the peak temperature, $T_{\mathrm{m}}$ denotes the melting point, $\omega$ denotes the rotation speed and $V$ denotes the welding speed. The constants $K$ and $\alpha$ lie within the ranges of 0.65-0.75 and 0.04-0.06, respectively.

Based on the welding parameters used in this study, the calculated peak temperature of the SZ was $947-1074{ }^{\circ} \mathrm{C}$, which indicated that the peak temperature of the $\mathrm{SZ}$ was higher than the $\mathrm{Ac}_{3}$. At this temperature, the completely austenite transformation occurred in the SZ during the process of welding, which was consistent with the characteristics presented by the microstructure. As compared to the SZ, the $\mathrm{TMAZ}_{\mathrm{AS}}$ had less linear cementite, but more short-rod and granular cementite (Fig. 5i), which indicated that the peak temperature of the $\mathrm{TMAZ}_{\mathrm{AS}}$ was slightly lower than that of

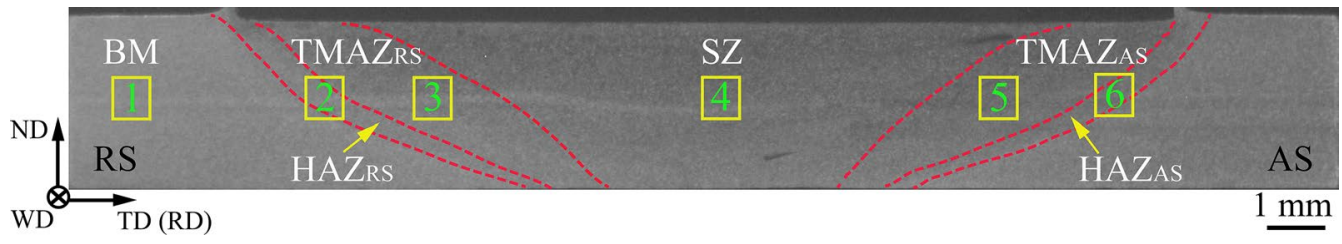

Fig. 3 Cross-sectional macrostructure of the FSW joint 

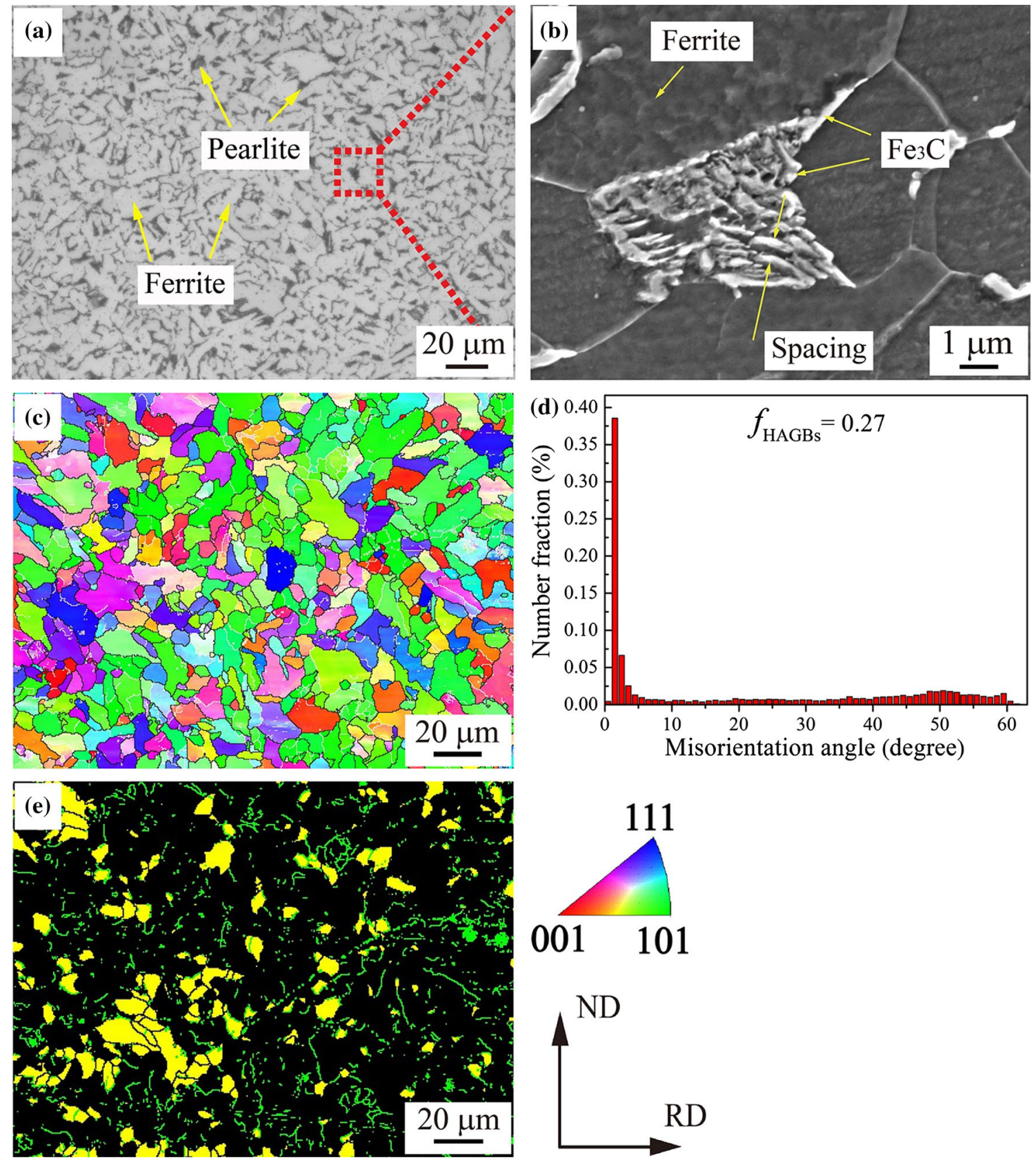

Fig. 4 Microstructures of the BM (zone 1 in Fig. 3): a OM, b SEM microstructure of the pearlite, $\mathbf{c}$ EBSD map, $\mathbf{d}$ misorientation angle distribution, e distribution of the recrystallized grains. The yellow indicates the recrystallized grains

SZ. The presence of the blocky ferrite, and more short-rod and granular cementite in $\mathrm{TMAZ}_{\mathrm{RS}}$ (Fig. 5b, g) indicated that the peak temperature of the $\mathrm{TMAZ}_{\mathrm{RS}}$ was between the $\mathrm{Ac}_{1}$ and $\mathrm{Ac}_{3}$, and the incomplete transformation to austenite occurred in the TMAZ $\mathrm{RS}_{\mathrm{S}}$ during the process of welding [8]. Besides, the recrystallization stopping temperature (RST) of the austenite could be calculated using Eq. (3) [38]. Based on the chemical composition of Q235 carbon steel, the RST value was found to be $927^{\circ} \mathrm{C}$, which was lower than the peak temperature of the $\mathrm{SZ}\left(947-1074{ }^{\circ} \mathrm{C}\right)$ and indicated that the SZ had undergone dynamic recrystallization in the austenite phase region [39].

$$
\begin{aligned}
\operatorname{RST}(\mathrm{C})= & 887+464^{\circ} \mathrm{C}+(6645 \mathrm{Nb}-664 \sqrt{\mathrm{Nb}}) \\
& +(732 \mathrm{~V}-230 \sqrt{V})+890 \mathrm{Ti}+363 \mathrm{Al}-357 \mathrm{Si} .
\end{aligned}
$$

Figure 6 shows the EBSD morphology of the grains in each zone of the joint. In the $\mathrm{HAZ}_{\mathrm{RS}}$ and $\mathrm{HAZ}_{\mathrm{AS}}$, the grains were more uniformly distributed and had the average grain 

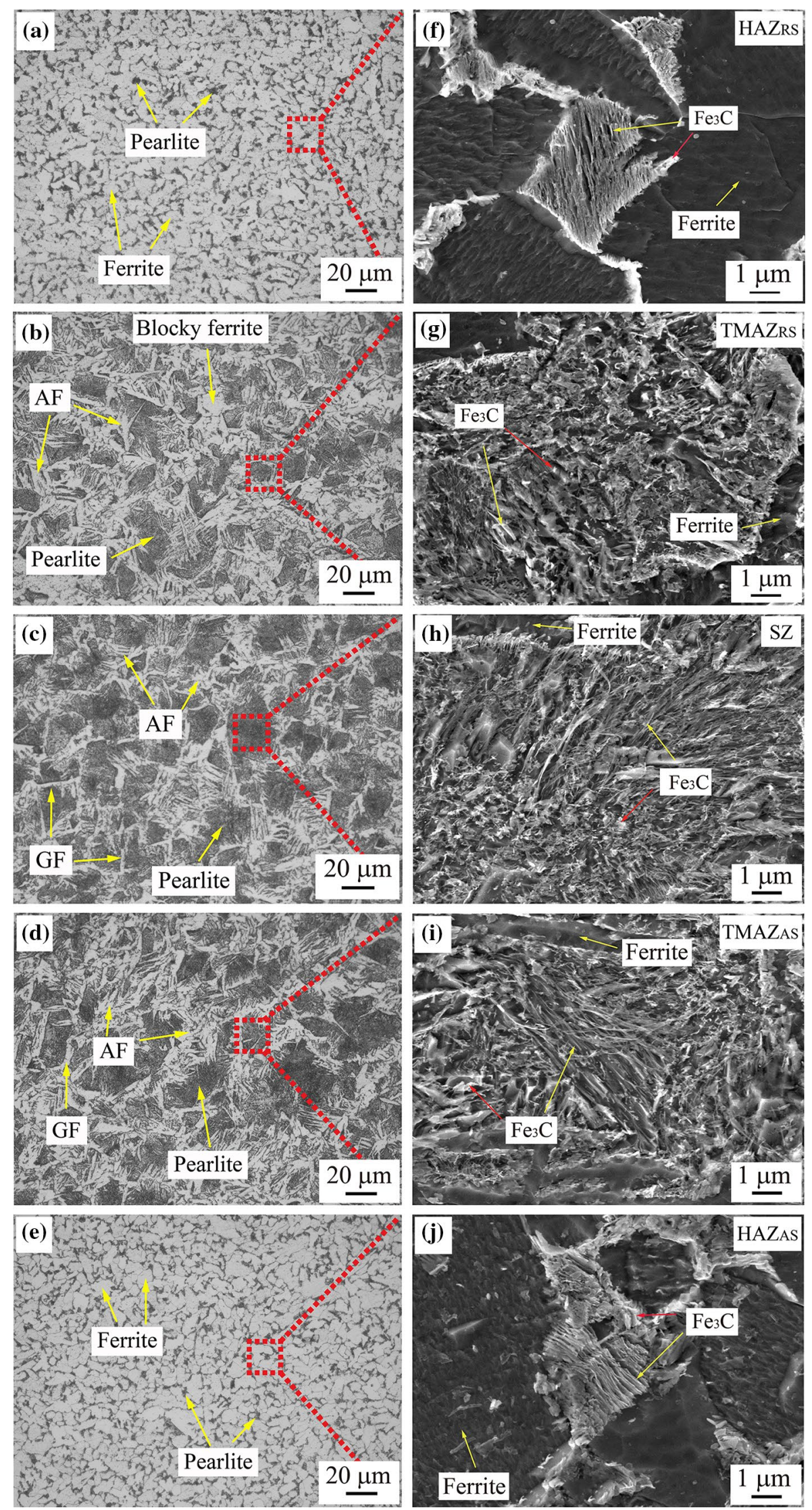
4 Fig. 5 Microstructures of the each zone in the joint, a-e OM microstructures of the $\mathrm{HAZ}_{\mathrm{RS}}, \mathrm{TMAZ}_{\mathrm{RS}}, \mathrm{SZ}, \mathrm{TMAZ}_{\mathrm{AS}}$, and $\mathrm{HAZ}_{\mathrm{AS}}$ (zones 2, 3, 4, 5 and 6 in Fig. 3), f-j SEM microstructures of the pearlite corresponding to the respective zones. The GF refers to the grain boundary ferrite, and the AF refers to the acicular ferrite

sizes of $5.87 \mu \mathrm{m}$ and $5.47 \mu \mathrm{m}$, respectively (Fig. 6a, e). As compared to the BM, the proportion of the HAGBs in the $\mathrm{HAZ}_{\mathrm{RS}}$ and $\mathrm{HAZ} \mathrm{Z}_{\mathrm{AS}}$ increased, which indicated that the $\mathrm{HAZ}_{\mathrm{RS}}$ and $\mathrm{HAZ}_{\mathrm{AS}}$ recovered during the process of FSW, which led to the migration or rearrangement of LAGBs and finally formed the HAGBs [39-42]. The habit planes of the acicular ferrite, produced by the phase transformations, were visible in the three regions of $\mathrm{TMAZ}_{\mathrm{RS}}, \mathrm{SZ}$ and TMAZ $_{\text {AS }}$ (Fig. 6b-d). Some previous studies have shown that the misorientation angles of the acicular ferrite were mainly distributed between $47^{\circ}$ and $60^{\circ}$ [43, 44]. It can be seen from the misorientation angle distribution of the three regions (Figs. 6f-h) that the sequence of the contents of the acicular ferrite was found in the descending order of: $\mathrm{TMAZ}_{\mathrm{RS}}>\mathrm{TMAZ}_{\mathrm{AS}}>\mathrm{SZ}$, which was consistent with the results of the $\mathrm{OM}$ analysis.

Figure 7 shows the proportions and variations in LAGBs, HAGBs, recrystallized grains (RXG) and the grain sizes in each zone of the joint. As compared to the $B M$, the average grain sizes of the $\mathrm{TMAZ}_{\mathrm{RS}}, \mathrm{SZ}$ and $\mathrm{TMAZ}_{\mathrm{AS}}$ reduced which was due to the refinement of the grains by the dynamic recrystallization. Figure 8 shows the morphology of the recrystallized grains in the $\mathrm{TMAZ}_{\mathrm{RS}}, \mathrm{SZ}$ and $\mathrm{TMAZ} \mathrm{AS}_{\mathrm{AS}}$. It can be seen that there were fine recrystallized grains inside the recrystallized grains (marked with the red arrow S). These fine grains indicated that the continuous dynamic recrystallization occurred in all the three zones during the process of FSW [8, 32]. Generally, for the single-phase alloys, the SZ undergoes a high temperature and a high strain rate, due to which its degree of recrystallization should have been high. However, the experimental results indicated that the proportion of the recrystallized grains in this region was lower (Fig. 7). This could be attributed to the fact that this zone underwent a phase transformation during the welding. The phase transformation generated a large amount of pearlite and then reduced the content of the ferrite, which underwent the dynamic recrystallization and had high stacking fault energy [39, 45, 46]. Furthermore, the proportion of the HAGBs in the SZ was low (Fig. 7), which was due to the high dislocation density of pearlite and acicular ferrite, which were generated by the phase transformations [37, 40]. Therefore, it could be seen that the characteristics of the microstructure of SZ were the result of the combined effects of the dynamic recrystallization and phase transformation.

Figure 9 shows the spatial orientation distribution functions (ODF) for the $\mathrm{TMAZ}_{\mathrm{RS}}, \mathrm{SZ}$ and $\mathrm{TMAZ}_{\mathrm{AS}}$, and the body-centered cubic structural components of the superimposed ideal shear texture [47-49]. The distributions of the orientation at two sections of $\varphi_{2}=0^{\circ}$ and $\varphi_{2}=45^{\circ}$ showed no components of the shear texture in the TMAZ $\mathrm{RS}_{\mathrm{RS}}$. The components of the $D_{1}, D_{2}$ and $F$ shear texture were visible in the SZ. However, the textures were weak, while only the component of the $\mathrm{F}$ shear texture existed in the $\mathrm{TMAZ}_{\mathrm{AS}}$ with a strong texture. Generally, the extent of the shear deformation is directly related to the components of the texture, which was generated by the deformation. The texture strength of the TMAZ $Z_{R S}, S Z$ and $\mathrm{TMAZ}_{\mathrm{AS}}$ changed from weak to strong, which indicated that the equivalent strain gradually increased from the $\mathrm{TMAZ}_{\mathrm{RS}}$ through $\mathrm{SZ}$ to $\mathrm{TMAZ}_{\mathrm{AS}}$. These results were consistent with the results of the study conducted by Saeid et al. [48]. Generally, the shear texture could be defined according to the crystallographic plane $\{h k l\}$ and the direction $\langle u v w\rangle$ parallel to the normal line $(Z)$ and the shear direction $(\theta)$ of the shear plane, respectively. In a metal having the body-centered cubic structure, the simple shear deformation is the ideal orientation formed by the two local fibers along $\{h k l\}\langle 111\rangle$ and $\{110\}\langle u v w\rangle$. Different components of the ideal shear texture included in the body-centered cubic structure are listed in Table 2. It can be seen that the main shear textures of the SZ were the $D_{1}$ $\{\overline{11} 2\}\langle 111\rangle, D_{2}\{11 \overline{2}\}\langle 111\rangle$ and the $F\{110\}\langle 001\rangle$. The TMAZ $_{\text {AS }}$ was mainly composed of $F\{110\}\langle 001\rangle$ shear texture.

\subsection{Mechanical Properties}

\subsubsection{Microhardness}

Figure 10a shows the cross-sectional distribution of the microhardness of the joint. The average microhardness of the BM was $131 \mathrm{HV}$. The hardness from the BM to SZ showed an increasing trend because with the decrease in the distance from the center of the weld, the contents of the pearlite and acicular ferrite caused by the phase transformation gradually increased and the effect of the grain refinement became gradually significant. Furthermore, the microhardnesses of the RS and AS were not completely symmetrically distributed at the center of the weld. The distribution of the hardness of the AS had a wider range, which was related to the higher strain and peak temperature experienced by the AS during the welding process [42, 47]. In addition, the maximum microhardness of $159 \mathrm{HV}$ occurred on the upper surface of the SZ (marked with the black arrow), which was due to the transformation of the localized bainite (Fig. 10b). Compared with the adjacent zones, the partial area of the SZ (marked with the red arrow) had significantly lower hardness. This was due to the fact that the incomplete transformation of austenite occurred in this area during the FSW process, whereas the structure 

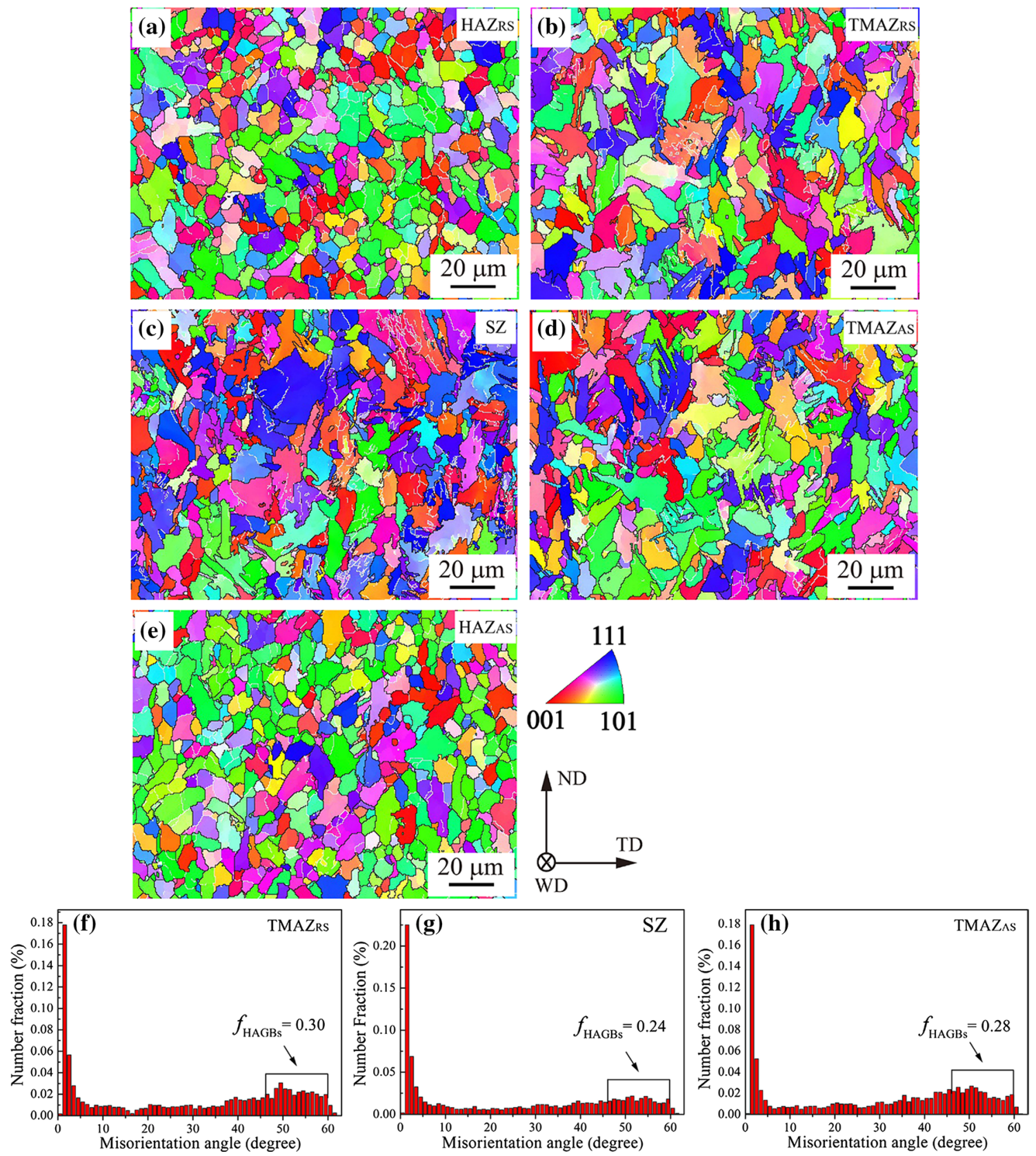

Fig. 6 EBSD microstructures in each zone of the joint: a-e HAZ $\mathrm{RS}_{\mathrm{RS}}, \mathrm{TMAZ}_{\mathrm{RS}}, \mathrm{SZ}, \mathrm{TMAZ}_{\mathrm{AS}}$, and $\mathrm{HAZ}_{\mathrm{AS}}$, respectively (zones 2, 3, 4, 5 and 6 in Fig. 3). $\mathbf{f}-\mathbf{h}$ misorientation angle distributions of the $\mathrm{TMAZ}_{\mathrm{RS}}, \mathrm{SZ}$, and $\mathrm{TMAZ}_{\mathrm{AS}}$, respectively. The misorientation angle of the $\mathrm{HAGBs}$ is larger than $15^{\circ}$, and the misorientation angle of the LAGBs is between $2^{\circ}$ and $15^{\circ}$, which are marked with the black and white lines, respectively

was composed of non-uniformly distributed ferrite and a small amount of pearlite (enlarged area in Fig. 10c). Figure 10d shows the distribution of microhardness at different thicknesses of the joint. The upper, middle and lower layers were $0.5 \mathrm{~mm}, 1.5 \mathrm{~mm}$ and $2.5 \mathrm{~mm}$ away from the joint's upper surface, respectively. It can be seen that the hardness gradually decreased from the top to bottom. This was due to the decrease in the number of pearlite and acicular ferrite generated by the phase transformation during FSW, which resulted in the difference in the hardness that was in the direction of the thickness [8].

\subsubsection{Tensile Properties}

Figure 11 shows the tensile properties of the joints of the FSW and the SZ specimens at room temperature. The tensile strengths of the BM, the joints of the FSW and the SZ specimens were $473 \mathrm{MPa}, 479 \mathrm{MPa}$ and $607 \mathrm{MPa}$, respectively, 


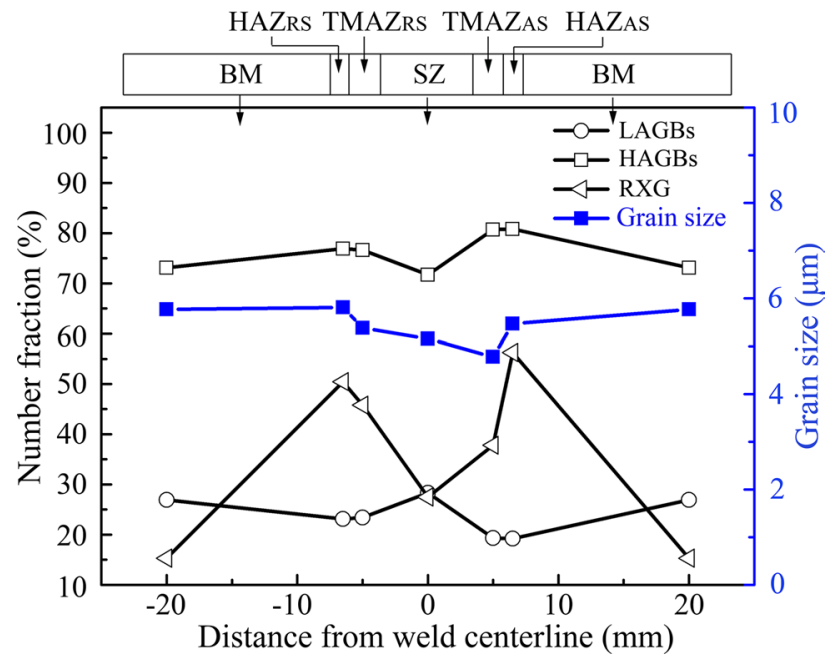

Fig. 7 Proportion of the LAGBs, HAGBs and recrystallized grain $(\mathrm{RXG})$ and the grain size in each zone of the joint while their uniform elongation (UE) was $24 \%, 16 \%$ and $19 \%$, respectively [51]. Compared with $\mathrm{BM}$, the tensile strengths of the joints of the FSW and the SZ specimens were increased by $1.3 \%$ and $22 \%$, respectively. The UE of the joint and the SZ was decreased by $33 \%$ and $21 \%$, respectively. The high tensile strength of the FSW joints was mainly due to the following two aspects: the phase transformation strengthening effect initiated by pearlite and acicular ferrite, and the fine-grained strengthening effect of ferrite. In addition, the reduction in the UE of joint was mainly related to the hard pearlite, which caused the mismatch in the joint strength and then resulted in the reduction in the UE [52].

Figure 12 shows the morphology of the macro- and micro-fractures of the joint. The joint fractures in the BM are shown in Fig. 12a. Figure 12b shows that the cracks propagated and fracture occurred along the pearlite interfaces (marked with yellow arrows), which indicated that the brittle pearlite was the main cause of the cracking. The tensile fracture showed the characteristics of plastic fracture (Fig. 12c). Compared with the BM fracture (Fig. 12d), the dimples were significantly shallower, indicating that the
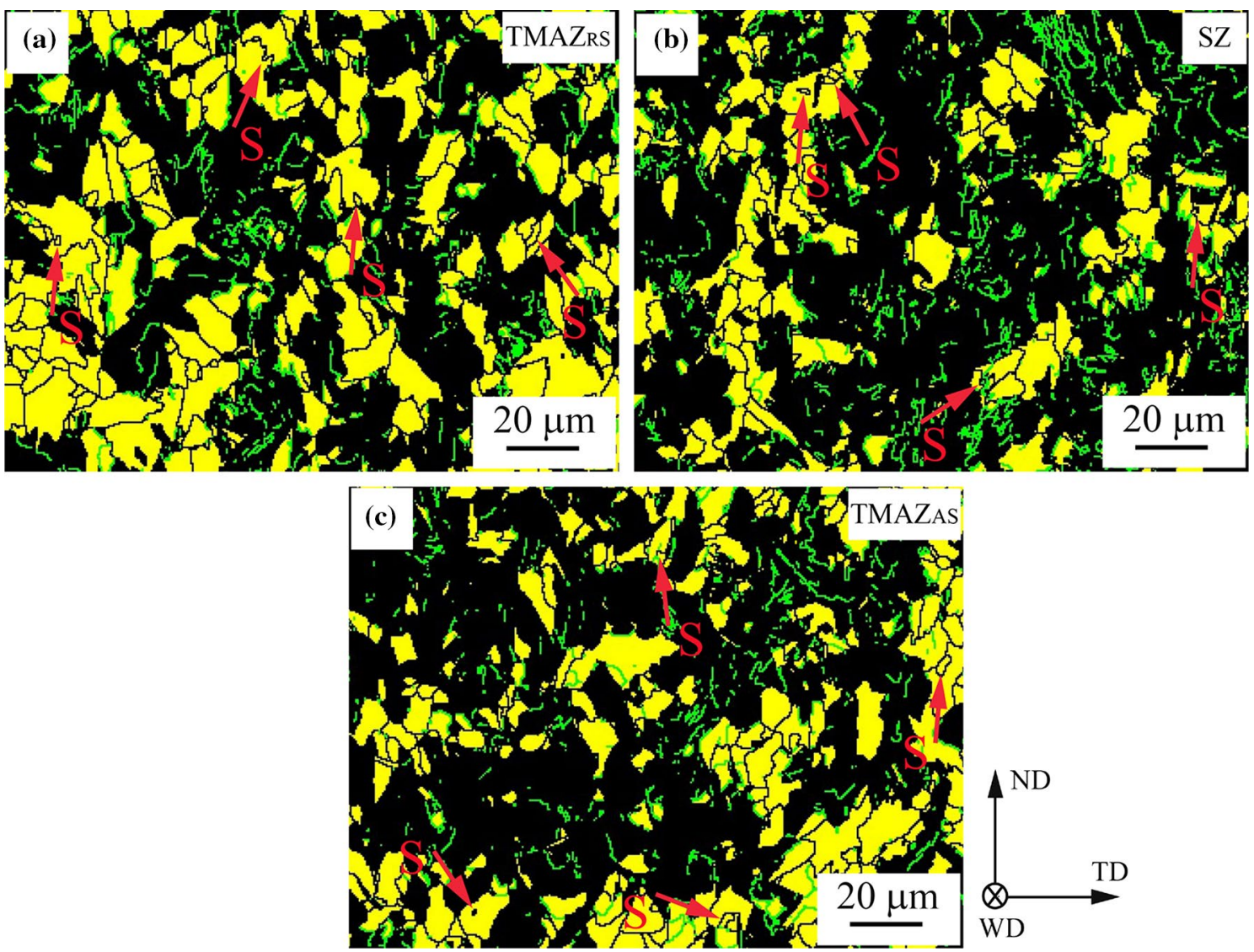

Fig. 8 Morphologies of the recrystallized grains in a TMAZ $\mathrm{RS}_{\text {, }}$, SZ, c $\mathrm{TMAZ}_{\mathrm{AS}}$ (zones 3, 4, and 5 in Fig. 3). Yellow indicates the recrystallized grains. The misorientation angle of the HAGBs is larger than $15^{\circ}$, and the misorientation angle of the LAGBs is between $2^{\circ}$ and $15^{\circ}$. Black and green lines represent the HAGBs and LAGBs, respectively 

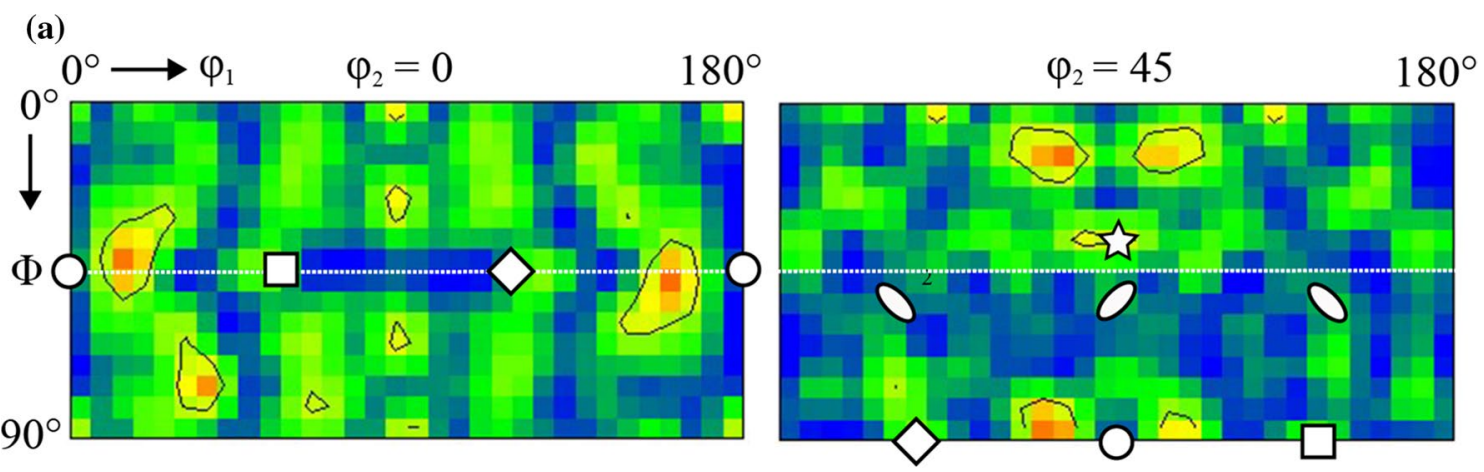

(b)
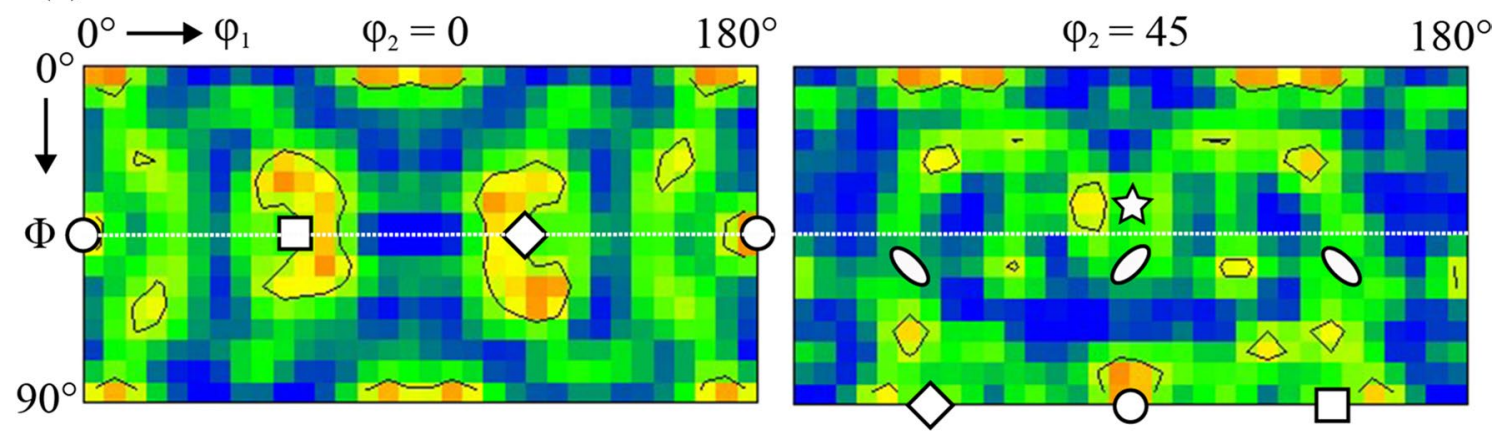

(c)
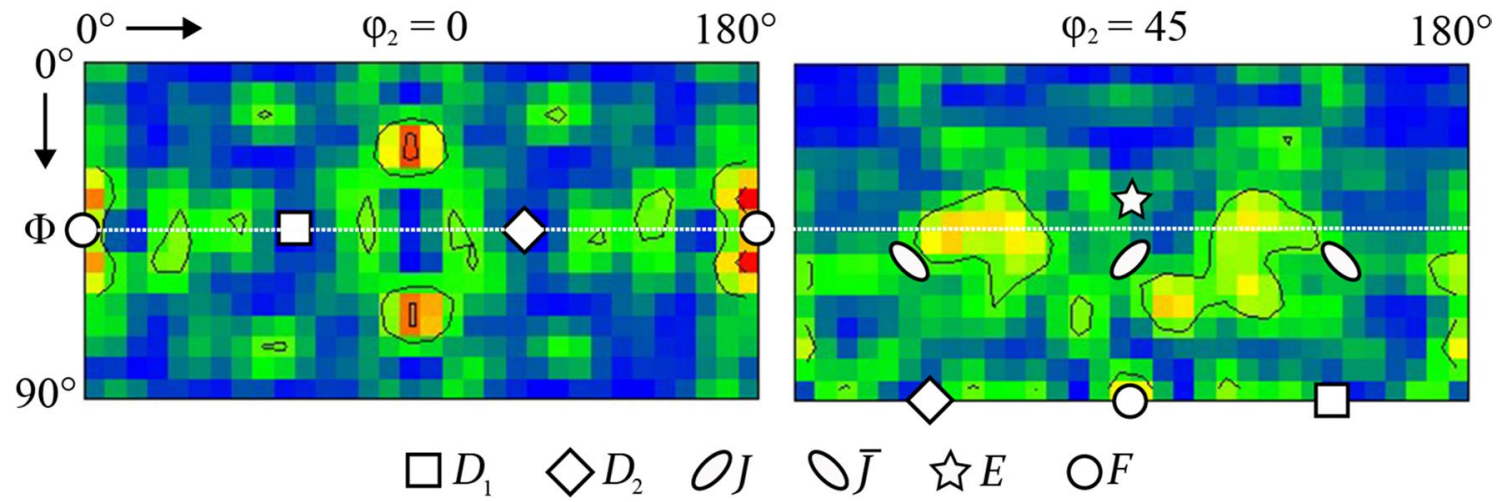

Fig. $9 \mathrm{ODF}$ at the cross sections of the $\varphi_{2}=0^{\circ}$ and $\varphi_{2}=45^{\circ}$ and the composition of the superimposed ideal shear texture of a body-centered cubic (bcc) metal, a TMAZ $\mathrm{RS}$, b SZ, c TMAZ $\mathrm{AS}$

plasticity of the FSW joint reduced, which was consistent with the UE data.

Figure 13 shows the morphology of the macro- and micro-fractures of the SZ specimen. The fractures in the specimen appeared in the middle of SZ (Fig. 13a). Figure $13 \mathrm{~b}$ shows that the propagation path of the crack in the coarse clusters of the pearlite was relatively straight (marked with the yellow arrow). In contrast, the propagation paths in the acicular ferrite packets were relatively tortuous (marked with the red arrow), which indicated that the acicular ferrite packets consumed more energy during the tensile deformation [53], which in turn effectively enhanced the elongation of the SZ. The characteristics of tensile fracture of the SZ specimen were consistent with those of the joint specimen. This also exhibited the characteristics of tough fracture. The densely packed dimples appeared due to the morphology of acicular ferrite after the tensile tests, while the larger and deeper dimples appeared due to the morphology of the coarse pearlite colonies after the tensile tests (Fig. 13c).

\subsubsection{Bending Performance}

The formation of the FSW joint was evaluated using the three-point bending tests. The face-bending and backbending specimens of the joints of the FSW were intact had no defects, such as the bending cracks and the fractures 
Table 2 Orientation of the ideal crystallographic in the simple shear deformation of a bcc metal [50]

\begin{tabular}{lllll}
\hline $\begin{array}{l}\text { Shear compo- } \\
\text { nent }\end{array}$ & $\{h k l\}\langle u v w\rangle$ & \multicolumn{3}{l}{ Euler angles (deg.) } \\
\cline { 3 - 5 } & & $\varphi_{1}$ & $\varphi$ & $\varphi_{2}$ \\
\hline$D_{1}$ & $\{\overline{1} \overline{1} 2\}\langle 111\rangle$ & $54.7 / 234.7$ & 45 & 0 \\
& & $144.7 / 324.7$ & 90 & 45 \\
$D_{2}$ & $11 \overline{2}\}\langle 111\rangle$ & $125.3 / 305.3$ & 45 & 0 \\
& & & & \\
$E$ & $\{110\}\langle 1 \overline{1} 1\rangle$ & $90.3 / 215.3$ & 90 & 45 \\
$\bar{E}$ & $\{\overline{110}\}\langle 1 \overline{1} 1\rangle$ & 270 & 35.3 & 45 \\
$J$ & $\{110\}\langle 1 \overline{1} 2\rangle$ & $90 / 210 / 330$ & 54.7 & 45 \\
$\bar{J}$ & $\{\overline{110}\}\langle\overline{1} 1 \overline{2}\rangle$ & $30 / 150 / 270$ & 54.7 & 45 \\
$F$ & & & 35.3 & 45 \\
& & $0 / 180$ & 45 & 0 \\
\hline
\end{tabular}

(Fig. 14a). Figure 14b shows the load-displacement curve of the bending. It can be seen that the FSW significantly increased the maximum bending force and the bending strength. The maximum bending force increased from $924 \mathrm{~N}$ to the face-bending force of $1427 \mathrm{~N}$ and the backbending force of $1317 \mathrm{~N}$. The bending strength increased from $756 \mathrm{MPa}$ to the face-bending strength of $994 \mathrm{MPa}$ and the back-bending strength of $970 \mathrm{MPa}$. These enhancements were related to the acicular ferrite and pearlite hardened structures, whereas the grain refinement was generated after the FSW [54-56]. In addition, the bending strength of the face-bending specimen was higher than that of the back-bending specimen. This was due to the higher hardness of the upper layer than the lower layer. On the other hand, for the specimens of the face-bending and the backbending of FSW joint, the displacements at the position with the maximum bending force of both the specimens reduced, while the specific value reduced from $22.63 \mathrm{~mm}$ to $15.53 \mathrm{~mm}$ for the face-bending and to $16.43 \mathrm{~mm}$ for the back-bending specimen, respectively. The reduction in the displacement was related to the hardened phase generated in the microstructure. Sekban et al. [56] have reported that the decrease in the displacement was due to the increase in the grain boundary fraction and the dislocation density of the microstructure.

\section{Conclusions}

1. The $H A Z_{R S}$ and $H A Z_{A S}$ recovered under the influence of heating cycles. The $\mathrm{TMAZ}_{\mathrm{RS}}, \mathrm{SZ}$ and $\mathrm{TMAZ}_{\mathrm{AS}}$ underwent a continuous dynamic recrystallization, the transformation of pearlite and the grain refinement. The characteristics of the microstructure were attributed to the combined action of the dynamic recrystallization and the phase transformations.

2. The SZ was mainly composed of $\{\overline{11} 2\}\langle 111\rangle$, $\{11 \overline{2}\}\langle 111\rangle$ and $\{110\}\langle 001\rangle$ shear textures. The TMAZAS had a $\{110\}\langle 001\rangle$ shear texture.

3. With the increase in the distance from the center of the weld, the microhardness of the FSW joint also increased, which was mainly due to the grain refinement and the formation of the pearlite and acicular ferrite. The maximum microhardness was located on the upper surface of the SZ.

4. The ultimate tensile strengths of the FSW joints and the SZ specimens were $479 \mathrm{MPa}$ and $607 \mathrm{MPa}$, respectively, and had the elongations of $16 \%$ and $19 \%$, respectively. Compared with of the ultimate tensile strength of BM, the ultimate tensile strengths of the FSW joints and the SZ specimens were increased by $1.3 \%$ and $22 \%$, respectively. The UE of the joint and the SZ was reduced by $33 \%$ and $21 \%$, respectively. The tensile fractures were the ductile fractures with the appearance of dimples.

5. The FSW enhanced the bending strength of Q235 steel. The strengths of the face-bending and the back-bending increased from 756 to $994 \mathrm{MPa}$ and to $970 \mathrm{MPa}$, respectively. However, the displacements, which corresponded to the loads of the face-bending and the back-bending, decreased from $22.63 \mathrm{~mm}$ to $15.5 \mathrm{~mm}$ and $16.43 \mathrm{~mm}$, respectively. 

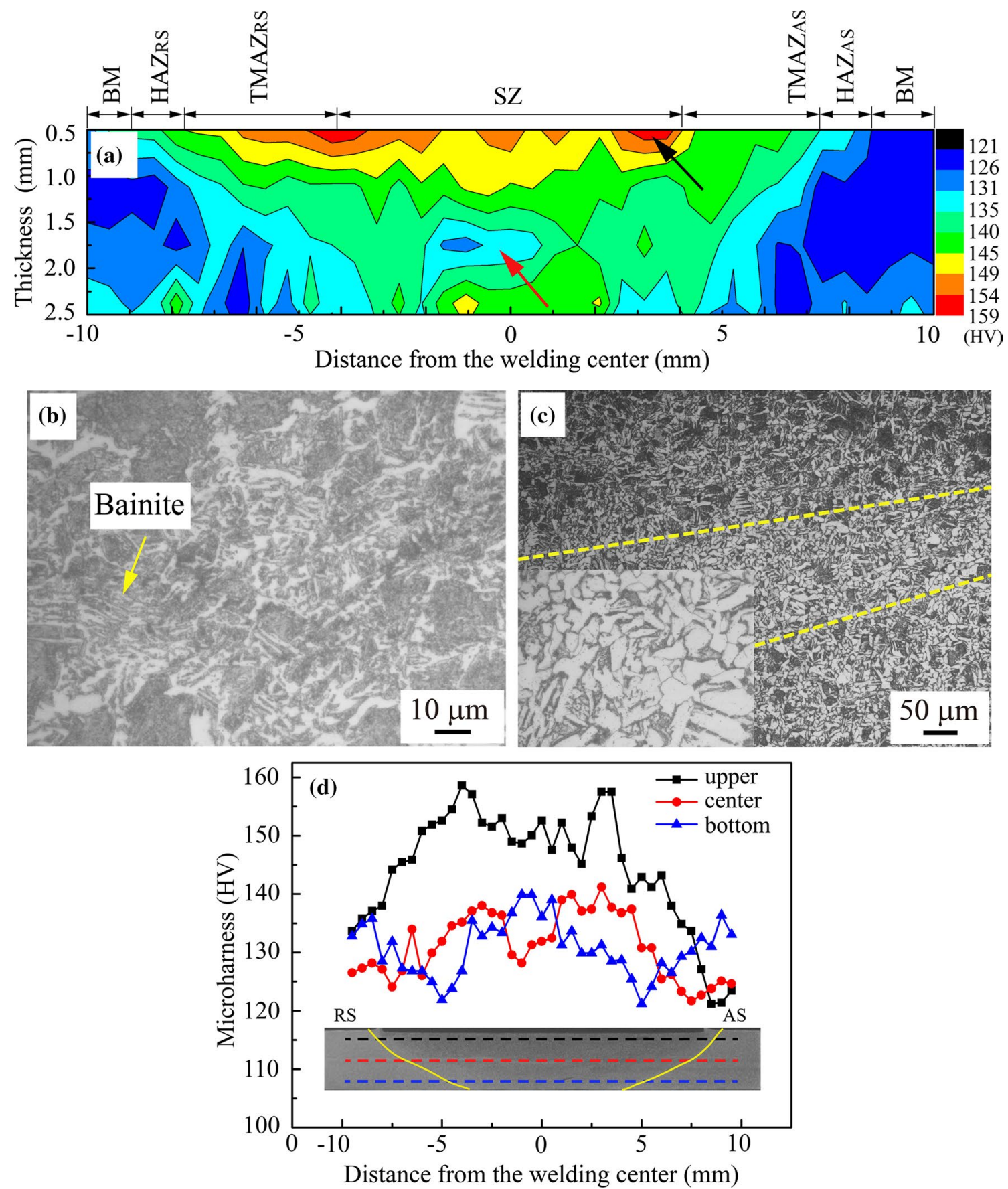

Fig. 10 a Distribution of the microhardness on the joint's cross section, $\mathbf{b}$ microstructure of the bainite, $\mathbf{c}$ microstructure underwent the incomplete transformation of the austenite, $\mathbf{d}$ distribution of the microhardness at different thicknesses of the joint 

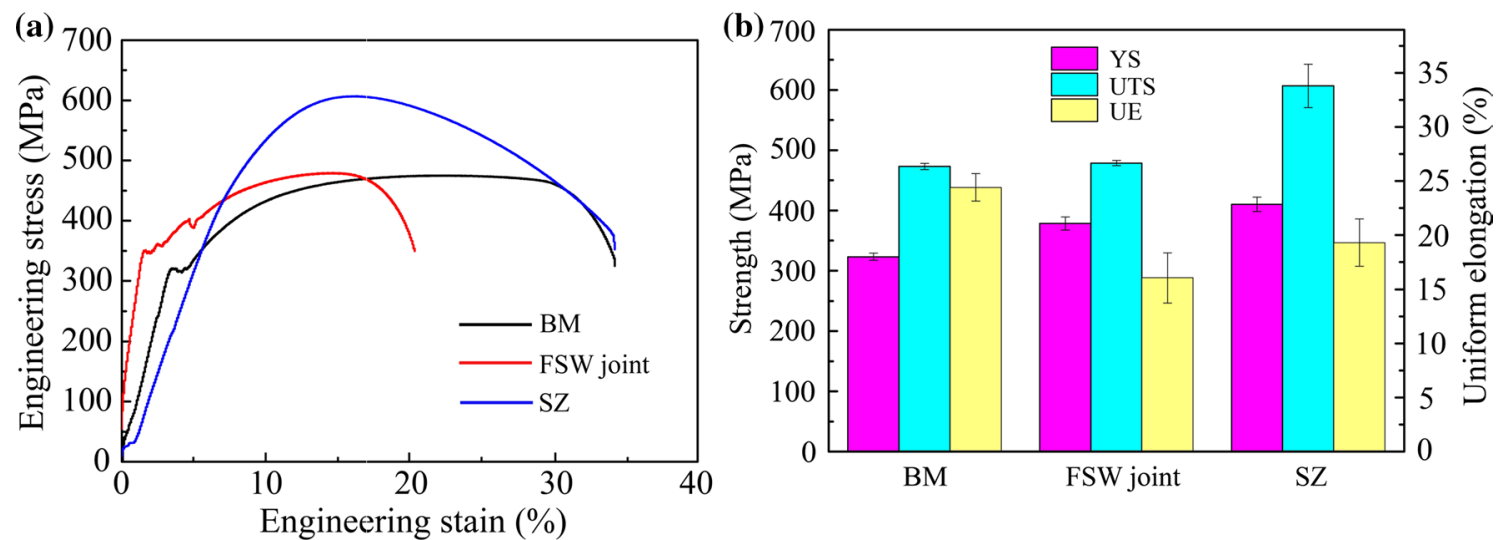

Fig. 11 Comparison of a the engineering stress-strain curves, $\mathbf{b}$ the mechanical properties of the BM, the joints of the FSW and SZ
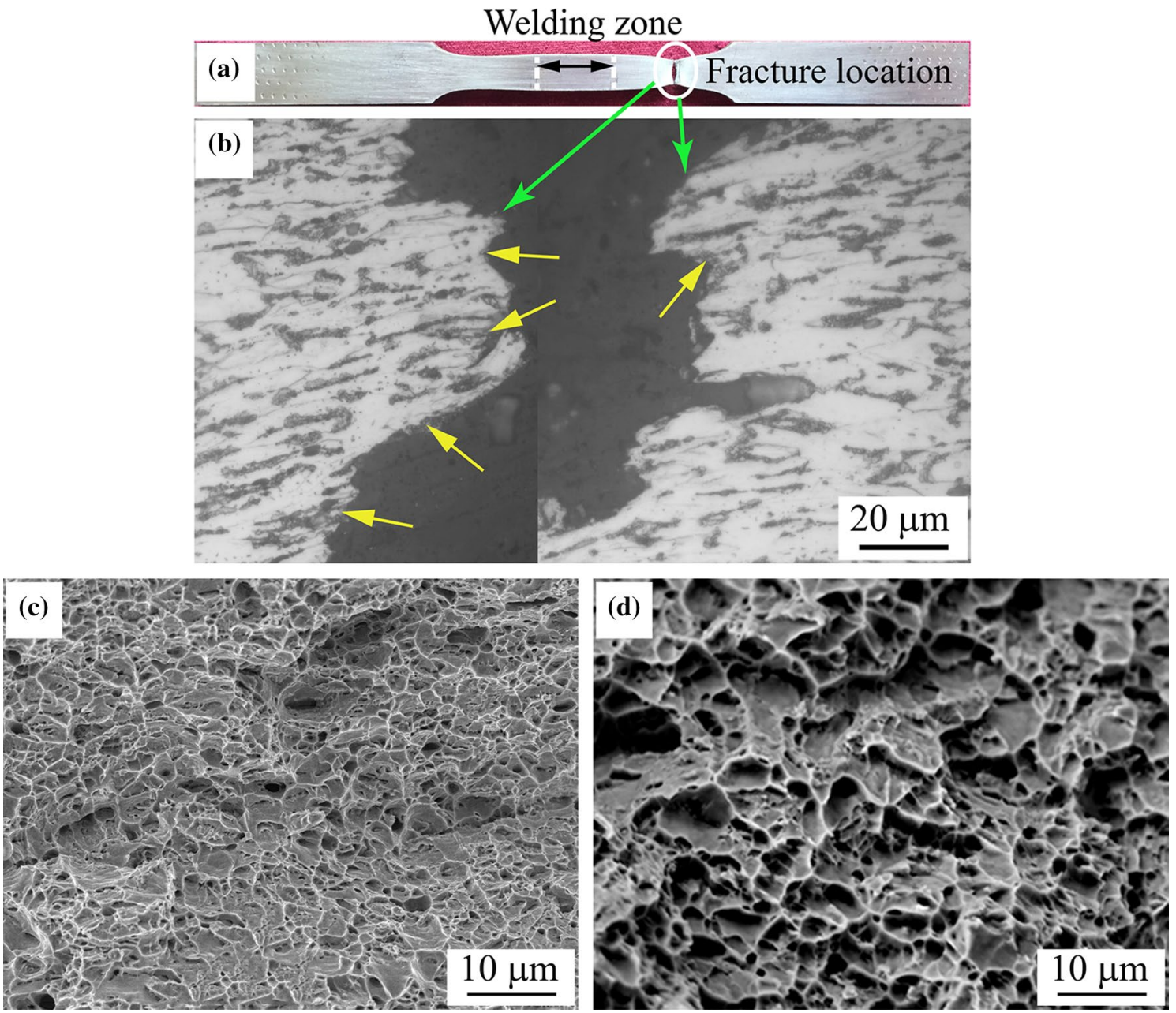

Fig. 12 a Fractured locations of the joint, b OM microstructure at the location of the fracture and the fracture SEM images of $\mathbf{c}$ FSW specimen, d BM 

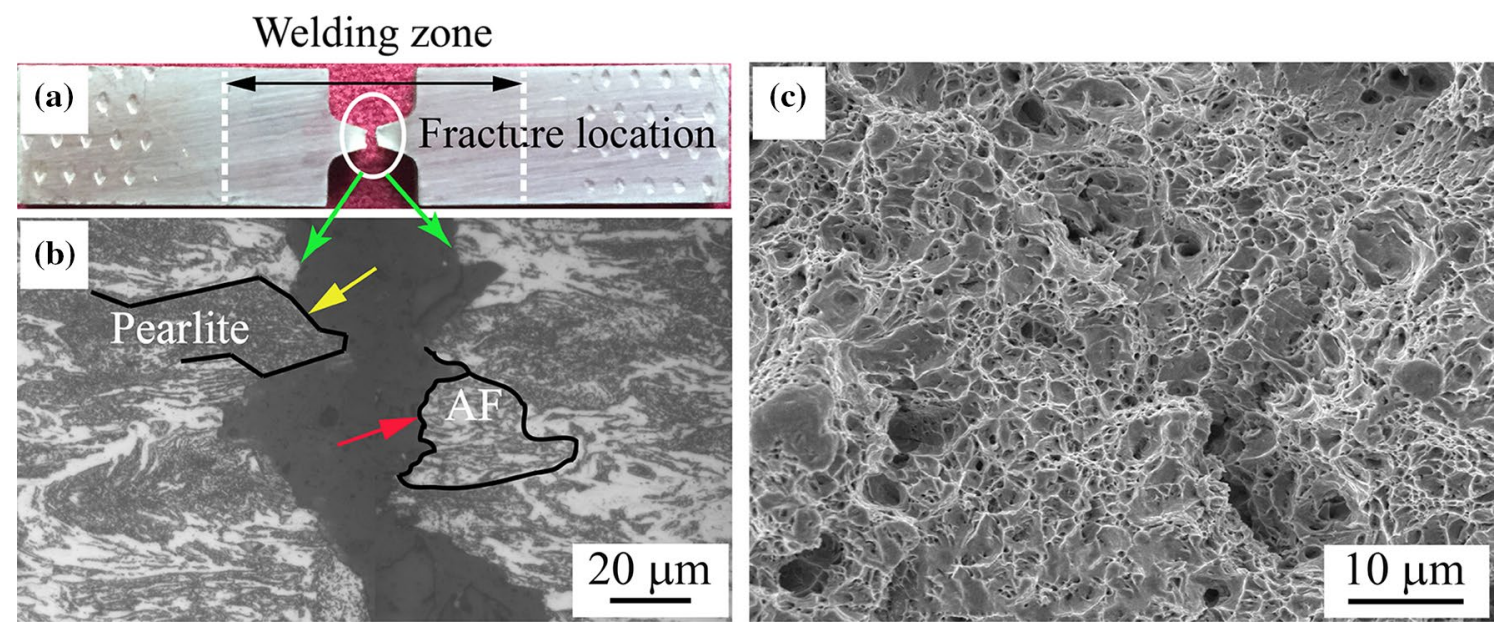

Fig. 13 a Position of the fractures of the SZ specimen, b OM microstructure of the position of the fracture, $\mathbf{c}$ SEM of the fracture of the SZ specimen. $A F$ acicular ferrite
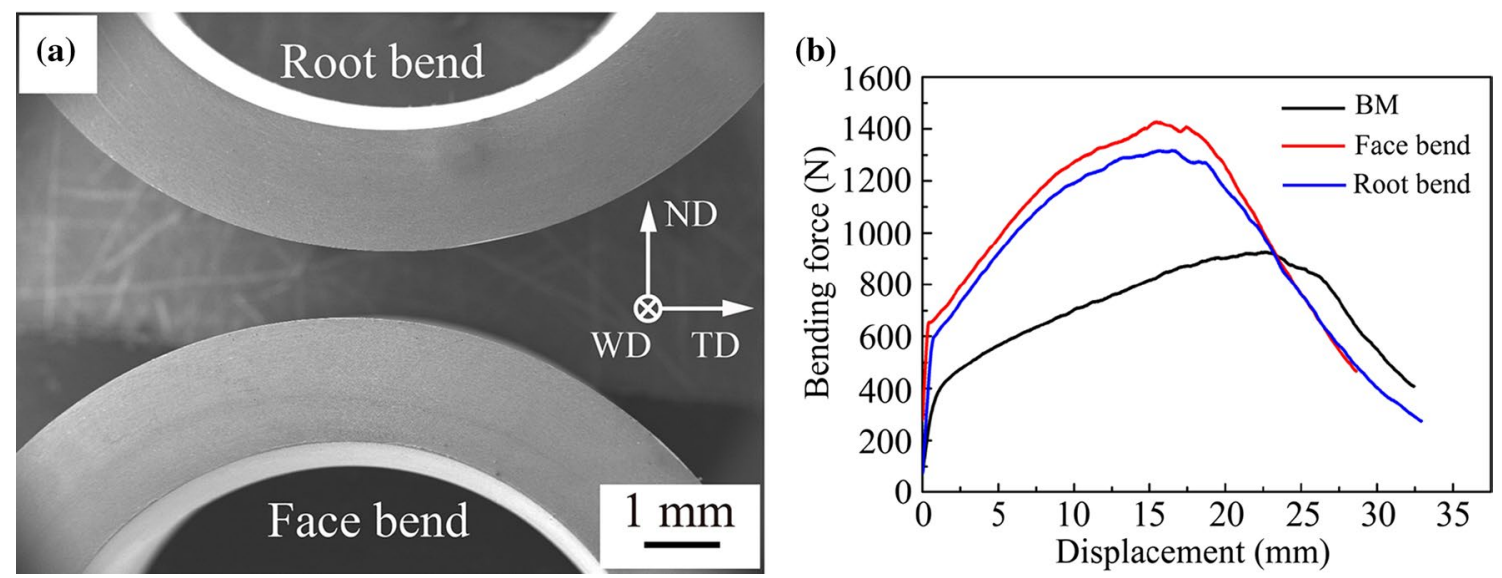

Fig. 14 a Macro-morphology of the specimens of the face-bending and back-bending of the joint, $\mathbf{b}$ bending load-displacement curves of the BM and the joints of the FSW

Acknowledgements This work was supported by the National Natural Science Foundation of China (Nos. 51974220, U1760201); the National Key Research and Development Program of China (No. Z20180407); the Natural Science Foundation of Shaanxi Province (No. 2019JQ-111); the Key Industrial Research Program of Shaanxi Province, China (No. 2017ZDXM-GY-037, 2020ZDLGY13-06); the Xi' an Science and Technology Project (No. 201805033YD11CG17(8)).

\section{References}

[1] A. De, H.K.D.H. Bhadeshia, T. Debroy, J. Mater. Sci. Technol. 30, $1050(2014)$

[2] S. Amandeep, G.N. Kanth, Appl. Mech. Mater. 813-814, 486 (2015)

[3] T. Ogawa, Int. J. Mech. Mater. Eng. 10, 1 (2015)

[4] A.G. Osorio, D. Souza, T. Passos, L. Dalpiaz, T. Aires, J. Mater. Process. Technol. 266, 46 (2018)
[5] Y. Sun, H. Fujii, H. Imai, K. Kondoh, Corros. Sci. 94, 88 (2015)

[6] Y. Azuma, Y. Kameno, T. Takasugi, Weld. Int. 27, 929 (2013)

[7] S.A. Khodir, Y. Morisada, R. Ueji, H. Fujii, Mater. Sci. Eng. A 558, $572(2012)$

[8] H.D. Wang, K.S. Wang, W. Wang, L.Y. Huang, P. Peng, H.L. Yu, Mater. Charact. 155, 109803 (2019)

[9] W.M. Thomas, E.D. Nicholas, J.C. Needham, M.G. Murch, P. Temple-smith, C.J. Dawes, International Patent Application No. PCT/GB92/02203 and GB Patent Application No. 9125978.8 and US Patent Application No. 5,460, 317 (1991)

[10] W.M. Thomas, C.J. Dawes, Weld. J. 75, 41 (1996)

[11] R.S. Mishra, Z.Y. Ma, Mater. Sci. Eng. R 50, 1 (2005)

[12] Z.K. Shen, Y.Q. Ding, A.P. Gerlich, Crit. Rev. Solid State Mater. Sci. (2019). https://doi.org/10.1080/10408436.2019.1671799

[13] H.B. Li, S.X. Yang, S.C. Zhang, B.B. Zhang, Z.H. Jiang, H. Feng, P.D. Han, J.Z. Li, Mater. Des. 118, 207 (2017)

[14] Y.X. Huang, Y.M. Xie, X.C. Meng, J.C. Li, L. Zhou, J. Mater. Sci. Technol. 35, 1261 (2019) 
[15] M. Guan, Y.H. Wang, Y.X. Huang, X. Liu, X.C. Meng, Y.M. Xie, J.C. Li, Mater. Lett. 255, 126506 (2019)

[16] H.J. Jiang, B. Zhang, C.Y. Liu, Z.X. Yang, Acta Metall. Sin. (Engl. Lett.) 32, 1135 (2019)

[17] W. Wang, P. Han, P. Peng, T. Zhang, Q. Liu, S.N. Yuan, L.Y. Huang, H.L. Yu, K. Qiao, K.S. Wang, Acta Metall. Sin. (Engl. Lett.) 33, 43 (2020)

[18] Y.F. Wang, J. An, K. Yin, M.S. Wang, Y.S. Li, C.X. Huang, Acta Metall. Sin. (Engl. Lett.) 31, 878 (2018)

[19] D. Lohwasser, Z. Chen (eds.), Friction Stir Welding: From Basics to Applications (Elsevier, Amsterdam, 2010)

[20] L.E. Murrr, Y. Li, E. Trillo, J.C.M. Clure, Mater. Technol. 15, 37 (2000)

[21] G.P. Dinda, A. Ramakrishnan, Int. J. Adv. Manuf. Technol. 103, $4763(2019)$

[22] X.C. Liu, Y.F. Sun, T. Nagira, H. Fujii, Mater. Charact. 137, 24 (2018)

[23] H. Fujii, L. Cui, N. Tsuji, M. Maeda, K. Nakata, K. Nogi, Mater. Sci. Eng. A 429, 50 (2006)

[24] Y.J. Li, R.D. Fu, Y. Li, Y. Peng, H.J. Liu, J. Mater. Sci. Technol. 34, 157 (2018)

[25] Z.W. Wang, G.M. Xie, D. Wang, H. Zhang, D.R. Ni, P. Xue, B.L. Xiao, Z.Y. Ma, Acta Metall. Sin. (Engl. Lett.) 33, 58 (2020)

[26] K. Kitamura, H. Fujii, Y. Iwata, Y.S. Sun, Y. Morisada, Mater. Des. 46, 348 (2013)

[27] Y. Zhang, Y.S. Sato, H. Kokawa, S.H.C. Park, S. Hirano, Mater. Sci Eng. A 485, 448 (2008)

[28] M.M.Z. Ahmed, B.P. Wynne, J.P. Martin, Sci. Technol. Weld. Join. 18, 680 (2013)

[29] S.M. Mousavizade, M. Pouranvari, F.M. Ghaini, H. Fujii, Y.F. Sun, J. Alloys Compd. 685, 806 (2016)

[30] Z. Iqbal, A. Bazoune, F.A. Badour, A. Shuaib, N. Merah, Arabian. J. Sci. Eng. 44, 1233 (2019)

[31] L. Zhou, R.X. Zhang, H.F. Yang, Y.X. Huang, X.G. Song, J. Mater. Eng. Perform. 27, 6709 (2018)

[32] MdM Husain, R. Sarkar, T.K. Pal, M. Ghosh, N. Prabhu, J. Mater. Eng. Perform. 26, 2047 (2017)

[33] J. Trzaska, L.A. Dobrza'nski, J. Mater. Process. Technol. 192-193, 504 (2007)

[34] ASTM E8/E8M, Standard Test Methods for Tension Testing of Metallic Materials, ASTM International, West Conshohocken, USA, (2013)
[35] British Standards Institution Destructive tests on welds in metallic materials -bend tests. BS EN ISO 5173+A1, London, (2011)

[36] N. Carbajal, F. Mujika, Polym. Test. 28, 150 (2009)

[37] G.R. Argade, S. Shukla, K. Liu, R.S. Mishra, J. Mater. Process. Technol. 259, 259 (2018)

[38] F. Borrato, R. Barbosa, S. Yue, J.J Jonas, Thermec-881, 383 (1988)

[39] H.H. Cho, S.H. Kang, S.H. Kim, K.H. Oh, H.J. Kim, W.S. Chang, H.N. Han, Mater. Des. 34, 258 (2012)

[40] G.M. Xie, R.H. Duan, P. Xue, Z.Y. Ma, H.L. Liu, Z.A. Luo, Acta Metall. Sin. (Engl. Lett.) 33, 88 (2020)

[41] Z.A. Zakaria, K.N.M. Hasan, M.F.A. Razak, Key. Eng. Mater. 740, 155 (2017)

[42] M. Imam, R. Ueji, H. Fujii, Mater. Sci. Eng. A 636, 24 (2015)

[43] A.F. Gourgues, H.M. Flower, T.C. Lindley, J. Mater. Sci. Technol. 16, $26(2000)$

[44] P. Xue, Z.Y. Ma, Y. Komizo, H. Fujii, Mater. Lett. 162, 161 (2016)

[45] T.F.A. Santos, E.A.T.L. Opez, E.B. Fonseca, A.J. Ramirez, Mater. Res. 19, 117 (2016)

[46] H. Fujii, L. Cui, K. Nakata, K. Nogi, Weld. World. 52, 75 (2013)

[47] S. Rahimi, T. Konkova, I. Violatos, T.N. Baker, Metall. Mater. Trans. A 50, 644 (2019)

[48] T. Saeid, A. Abdollah-zadeh, T. Shibayanagi, K. Ikeuchi, H. Assadi, Mater. Sci. Eng. A 527, 6484 (2010)

[49] S. Sabooni, F. Karimzadeh, M.H. Enayati, A.H.W. Ngan, Mater. Des. 76, 130 (2015)

[50] R.W. Fonda, K.E. Knipling, Sci. Technol. Weld. Join. 16, 288 (2011)

[51] P. Xue, W.D. Li, D. Wang, W.G. Wang, B.L. Xiao, Z.Y. Ma, Mater. Sci. Eng. A 670, 153 (2016)

[52] A.M.E. Batahgy, T. Miura, R. Ueji, H. Fujii, Mater. Sci. Eng. A 651, 904 (2016)

[53] G.M. Xie, H.B. Cui, Z.A. Luo, R.D.K. Misra, G.D. Wang, Mater Sci. Eng. A 704, 401 (2017)

[54] D.M. Sekban, S.M. Akterer, O. Saray, Z.Y. Ma, G. Purcek, J. Mater. Sci. Technol. 34, 237 (2018)

[55] D.M. Sekban, O. Saray, S.M. Aktarer, G. Purcek, Z.Y. Ma, Mater. Sci. Eng. A 642, 57 (2015)

[56] D.M. Sekban, S.M. Aktarer, G. Purcek, Metall. Mater. Trans. A 50, 4127 (2019) 